\title{
Use and Properties of Blast Furnace Slag as a Building Material- A Review
}

\author{
http://dx.doi.org/10.3991/ijes.v2i4.4211 \\ Mohit Jain \\ Nirma University, Ahmedabad, India
}

\begin{abstract}
This paper aims at bringing a literature review on the uses and properties of popular industrial and mineral byproduct slag. At the present, most industrial slags are being used without taking full advantage of their properties or disposed rather than used. The use of slag in replacing Portland cement by GGBFS is not very common. The traditional way to utilize metallurgical slags in cementing materials is to partially replace Portland cement. The practice of using such mineral admixtures in construction will reduce the need of portland cement and its use in various parts of the world, thus greatly reducing the amount of pollution and pave a way for a cleaner and more economical construction material, of which India is in a great need.
\end{abstract}

The literary investigation was carried out on different forms of slag used in construction, i.e. slag aggregates, ground granulated blast furnace slag (GGBFS) and slag mixed with clinker in cement production. Many different properties were examined during the literature review, all segregated into separate categories based on the type of usage, particle size and chemical composition. The base samples ranged from cement sample to meter cubes, beams and concrete cubes. The properties investigated from various sources of literature were hydration, reactivity, hydraulic power and slump loss. Also properties related to durability and environmental effects like cabonation depth, chloride resistance, sulphate resistance, percentage of water absorption, heat resistance and resistance to freeze and thaw cycles are also discussed. Its activation with innovative methods and certain reasons were found out which attributed to such behaviour such as glass content, microstructure, $\mathrm{pH}$ nature, pore size etc.

The behaviour of concrete samples were also investigated with some agents, i.e. samples with some extra chemical admixtures, air entraining agents. Also differentiation was done on the basis of formation of slag aggregates, i.e. the variation in properties of slag based construction materials vary when slag is created employing different techniques. The investigation will also explain the different problems faced by civil engineers in using slag as a major component in building materials.

Index Terms-Blast Furnace Slag, use, properties

\section{INTRODUCTION}

Waste utilization is an attractive alternative to disposal in that disposal cost and potential pollution problems are reduced or even eliminated along with the achievement of resource conservation. Nevertheless, the utilization strategy must be coupled with environmental and energy considerations to use available materials most efficiently.

\section{A. Production of slag}

Slag cement begins in an iron blast furnace. Carefully controlled amounts of iron ore, along with limestone or dolomite, are fed into a blast furnace and heated to 2,700 degrees F. When molten, the iron is tapped for steel production and the slag is diverted to a granulator. Here, the slag is rapidly quenched with large quantities of water. The process minimizes crystallization and forms "granulated slag," which is composed principally of calcium aluminosilicate glass. (Formation of this glass provides slag cement with its cementitious properties.) At this point, the slag is the consistency of fine sand. It is then dewatered and dried. Finally, the slag is ground to a fine powder and becomes slag cement, or it is interground with portland cement clinker to make a blended cement.

Blast furnace slag has a constitution of basic elements a bit different than Ordinary portland cement [8] as shown here in (table 1).

TABLE I.

A COMPARATIVE ANALYSIS OF DIFFERENT CONSTITUENTS (PERCENTAGE WISE) OF SLAG AND OPC.

\begin{tabular}{|c|c|c|}
\hline Constituent/property & Slag & $\mathrm{OPC}$ \\
\hline $\mathrm{SiO}_{2}(\%)$ & 35.04 & 19.9 \\
\hline $\mathrm{Al}_{2} \mathrm{O}_{3}(\%)$ & 13.91 & 4.62 \\
\hline $\mathrm{Fe}_{2} \mathrm{O}_{3}(\%)$ & 0.29 & 3.97 \\
\hline $\mathrm{M} \mathrm{IgO}_{\mathrm{g}}(\%)$ & 6.13 & 1.73 \\
\hline $\mathrm{CaO}(\%)$ & 39.43 & \\
\hline $\mathrm{Na}_{2} \mathrm{O}(\%)$ & 0.34 & \\
\hline $\mathrm{TrO}_{2}(\%)$ & 0.42 & \\
\hline $\mathrm{K}_{2} \mathrm{O}(\%)$ & 0.39 & 0.57 \\
\hline $\mathrm{P}_{2} \mathrm{O}_{5}(\%)$ & $<0.1$ & \\
\hline $\mathrm{MInO}(\%)$ & 0.43 & \\
\hline Total sulphur as $\mathrm{SO}_{3}(\%)$ & 2.43 & 2.56 \\
\hline Sulphide sulphur as $S^{2}$ & 0.44 & \\
\hline $\mathrm{Ol}(\mathrm{ppm})$ & 80 & \\
\hline Fineness $\left(\mathrm{m}^{2} / \mathrm{kg}\right)$ & 460 & 342 \\
\hline
\end{tabular}

\section{B. History of Slag Cement?}

Slag cement use can be traced to the 1700 s, when the material was combined with lime to make mortars. The first U.S. production was in 1896. Until the 1950s, granulated slag was used in the manufacture of blended portland cements, or as raw feedstock to make cement clinker. However, the 1950s saw slag cement become available in other countries as a separate product. The first granulation facility in the U.S. to make a separate slag cement product was Sparrows Point, Maryland, in the early 1980s. Recent years have seen the supply and acceptance of slag cement grow dramatically throughout the U.S. 


\section{Today's scenario in Slag Utilization}

Today fifty million tons per year of steel slag are produced as a residue in the world. At the present, most industrial slags are being used without taking full advantage of their properties or disposed rather than used. The industrial slags, which have cementitious or pozzolanic properties, should be used as partial or full replacement for Portland cement rather than as bulk aggregates or ballasts because of the high cost of Portland cement, which is attributable to the high energy consumption for the production of Portland cement. The traditional way to utilize metallurgical slags in cementing materials is to partially replace Portland cement, which usually results in a lower early strength and longer setting times.

\section{Environmental Benefits of Using Slag Cement}

Production of slag cement creates a value-added product from a material - blast furnace slag - that otherwise might be destined for disposal. The manufacture of slag cement not only lessens the burden on landfills, but also reduces air emissions at steel plants through the granulation process (as compared to the traditional air-cooling process). Use of slag cement in concrete reduces the environmental impact of concrete by:

1. Reducing greenhouse gas emissions by eliminating approximately one ton of carbon dioxide for each ton of portland cement replaced.

2. Reducing energy consumption, since a ton of slag cement requires nearly 90 percent less energy to produce than a ton of portland cement.

3. Reducing the "urban heat island" effect by making concrete lighter in color, enabling it to reflect more light and cooling structures and pavements with exposed concrete.

The Environmental Protection Agency recognizes the environmental benefits of using slag cement in concrete. It has classified slag cement as a "recovered" product under the Resource Conservation Recovery Act (RCRA), and has issued a procurement guideline requiring its specification on most federally-funded projects.

\section{RELIABLE FORM OF SLAG FOR MAXIMUM UTILIZATION}

\section{A. Type of slag, Air cooled or Water cooled}

Water-granulated blast-furnace slag has the consistency of sand, and must be finely ground for use as a cementing material in concrete. In addition to the economy gained from use of slag as a partial replacement for the cement, there are large savings in energy requirements for the final product. Total energy consumption in processing and grinding the slag is far less than that necessary for the production of Portland cement. Although water quenched Blast furnace Slag has been used to produce Slag cement for a long time, Air cooled BFS and Steel making slags are not used frequently. This is because such types of slags are hydraulically unreactive. It was found that Air cooled and water cooled BFS do not have huge differences in their chemical composition [6]. The following table makes it very clear that both materials have nearly same composition of the major components. The minerological composition of Air cooled Slag identified from $\mathrm{XRD}$ reveals that the main mineral is gehlenite $\left(\mathrm{Ca}_{2} \mathrm{Al}_{2} \mathrm{SiO}_{7}\right)$. It was found that both materials could fullfill the IS specifications given in IS:12089-1987 [2]. But, AS does not full fill the glass requirement.

The basicity of WS was 1.45 and that of AS was 1.37 , using $\left(\mathrm{Cao}+\mathrm{MgO}+1 / 3 \mathrm{Al}_{2} \mathrm{O}_{3}\right) /\left(\mathrm{SiO}_{2}\right)$

From the experiments conducted by N.Y. Mostafa et al [6]. it was found that as expected WS showed higher activity than AS. The pozzolonic activity tests show that AS is also hydraulically active but the intensity is lower than WS. Thus for slag cements WS must be preferred.

TABLE II.

A COMPARATIVE ANALYSIS OF DIFFERENT CONSTITUENTS (PERCENTAGE WISE) OF AIR COOLED AND WATER COOLED SLAG.

Chemical composition of AS and WS

\begin{tabular}{|c|c|c|c|c|c|c|c|c|c|c|c|c|c|c|}
\hline & $\mathrm{SiO}_{2}$ & $\mathrm{CoO}$ & $\mathrm{Al}_{2} \mathrm{O}_{3}$ & $\mathrm{Fe}_{2} \mathrm{O}_{3}$ & B 20 & Mgo & Mrro & $\mathrm{TiO}_{2}$ & $\mathrm{Na}_{2} \mathrm{O}$ & $\mathrm{K}_{2} \mathrm{O}$ & $\mathrm{SO}_{3}$ & $s^{2}$ & LI & Total \\
\hline Is & 34.2 & 36.5 & 10.5 & 0.44 & 5.31 & 2.45 & 6.24 & 0.72 & 1.84 & 0.71 & 0.01 & 0.95 & 0.98 & 99.2 \\
\hline$A_{2} S$ & 35.3 & 36.2 & 10.8 & 1.87 & 6.63 & 1.35 & 4.48 & 0.46 & 1.47 & 0.43 & 0.01 & 0.75 & 0.80 & 99.7 \\
\hline
\end{tabular}

Negative values due to the exidation of sulfide and ferreus iren.

\section{B. Particle size for usage}

In an experimentation was carried out by J.I. EscalanteGarcia et al [12], where concretes based on OPC-BFS were formulated to obtain 28 days design strengths of 15 , 20 and $25 \mathrm{MPa}$, The binder consumption levels were of approximately 230, 280 and $330 \mathrm{~kg} / \mathrm{m} 3$; and with BFS substitution for OPC at $0,30,50$ and $70 \mathrm{wt} . \%$. The Granulated blast furnace slag (AHMSA, Monclova, Mexico) used in the experimentation was ball milled to a relatively low Blaine surface area of $2900 \mathrm{~m} 2 / \mathrm{g}$.

The design strengths were attained, higher strengths were noted as the binder consumption was increased. As a general pattern, it was noted that in the presence of BFS, the strengths reduced as the \%BFS increased, more notoriously as the binder consumption increased [15].

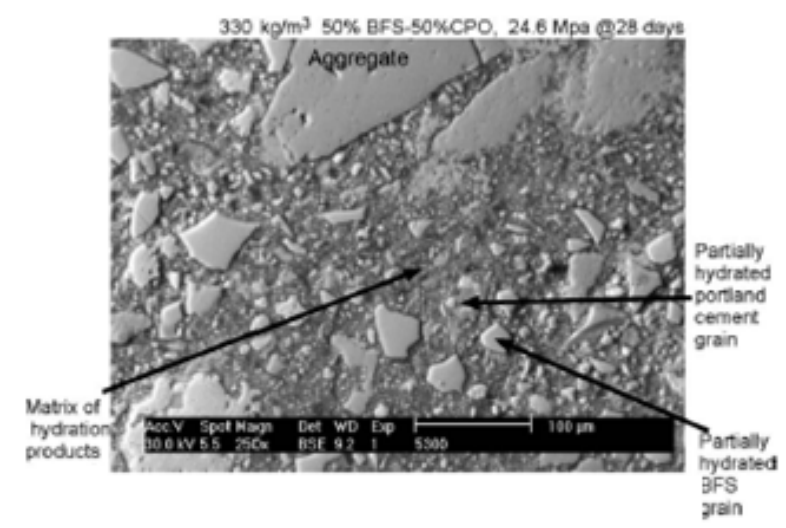

Figure 1. Images from Scanning Electron microscopy of the microstructure of polished samples of concrete OPC-BFS obtained by backscattered electron images as observed by J.I. Escalante-Garcia et al[12]. 
However It was observed that as the fineness of the BFS particles increased, the strengths improved and so did the microstructure. Now, Blast furnace Slag could also be used in concrete as fine aggregates. It was found through experimentation that GGBFS/sand ratio was the governing criteria for the effects on the strength and durability characteristics [14]. While strength decreased in some percentage, its replacement of sand particles had positive effects on durability characteristics of concrete. Thus it can be used in low and normal strength concretes. It was suggested an approximate replacement of sand by $50 \%$ [14], but the only condition one has to keep in mind while using slag as a replacement for fine aggregate was to use a sub-type sand which is finer than the slag particles. Keeping the results in mind, the use of slag as a replacement for fine aggregates can be allowed in building units like concrete bricks or blocks, where durability is a more important criterion than strength [7].

\section{PROPERTIES}

\section{A. Hydration Process}

The hydration of slag-blended cement is studied by considering the interaction between the hydrations of slag and Portland cement clinker. The main hydration products of Portland cement include C-S-H, CH, C4AH13, ettringite, hydrogarnet and monosulfate[1,10].

Three reaction models were investigated by W. Chen [10] for the slag-blended cement based on stoichiometric calculations. The model predictions are further used to calculate some properties of hydrating slag cement pastes, including the molar fractions of products, the water retention, chemical shrinkage and porosities of pastes. The two ingredients (Portland cement and slag) hydrate at different rates. After being mixed with water, Portland cement in the blended cement starts to hydrate immediately. Meanwhile, a small amount of GGBFS reacts, probably due to the presence of gypsum in cement. Then, the hydration of slag is greatly activated by alkalis and later by the Portlandite released by the hydration of Portland cement. Generally, the slag hydration rate is far lower than that of clinker. After one year, about $90 \%-100 \%$ of the clinker has hydrated in the blended cement paste. At the same age, only about $50 \%-70 \%$ of the slag has hydrated[1].

The $\mathrm{Al}_{2} \mathrm{O}_{3}$ content in slag is first combined with $\mathrm{MgO}$ to form the hydrotalcite and with $\mathrm{SiO}_{2}$ to form the ettringite. The remaining $\mathrm{Al}_{2} \mathrm{O}_{3}$ enters $\mathrm{C}-\mathrm{S}-\mathrm{H}$ to substitute for $\mathrm{S}$. If the maximum degree of $\mathrm{Al}_{2} \mathrm{O}_{3}$ substitution is achieved, the remaining $\mathrm{Al}_{2} \mathrm{O}_{3}$ reacts to the AFm phase (C4AH13). The composition of hydrotalcite is related to the natural mineral $\mathrm{M}_{6} \mathrm{ACH}_{12}$. But the $\mathrm{MgO}^{-} / \mathrm{Al}_{2} \mathrm{O}_{3}$ ratio in the slag hydration product is not fixed to six and differs over a wide range. Pure phase hydrotalcite is difficult to distinguish in the hardened cement paste because it is closely mixed with $\mathrm{C}-\mathrm{S}-\mathrm{H}$. AFm phases, including the tetracalcium aluminate hydrate $\left(\mathrm{C}_{4} \mathrm{AH}_{13}\right)$ and stratlingite $\left(\mathrm{C}_{2} \mathrm{ASH}_{8}\right)$ are found in the hydration products of pure slag[10].

Furthermore, since most reaction models available for Portland cement hydration are based on the hydration of the individual clinker phases, the hydrations of calcium silicates are assumed not to interact with the hydration of the other clinker phases (aluminate and ferrite) in Portland cement. The reactions of aluminate are represented by the following equations $[1,10]$.

$$
\begin{aligned}
& \mathrm{C}_{3} \mathrm{~A}+\mathrm{CH}+12 \mathrm{H} \rightarrow \mathrm{C}_{4} \mathrm{AH}_{13} \\
& 2 \mathrm{C}_{3} \mathrm{~A}+\mathrm{CC}+\mathrm{CH}+23 \mathrm{H} \rightarrow 2 \mathrm{C}_{4} \mathrm{AC}_{0.5} \mathrm{H}_{12} \\
& \mathrm{C}_{3} \mathrm{~A}+3 \mathrm{CSH}_{2}+26 \mathrm{H} \rightarrow \mathrm{C}_{6} \mathrm{AS}_{3} \mathrm{H}_{32}
\end{aligned}
$$

in which full carbonation of monosulfate (an intermediate product from the reaction of $\mathrm{C} 3 \mathrm{~A}$ with sulfate) takes place. In real hydrating cement pastes, ettringite is firstly formed from C3A and gypsum. Then, it is converted into monosulfate. However, the monosulfate is not commonly observed in mature cement pastes. The absence of monosulfate in cement pastes was found to be caused by carbonation. The carbonation effect finally converts the monosulfate into ettringite and hemicarbonate or monocarbonate. Therefore, in his study, the formation of ettringite from $\mathrm{C} 3 \mathrm{~A}$ is considered. The remaining $\mathrm{C} 3 \mathrm{~A}$ reacts with the $\mathrm{CH}$ to $\mathrm{C}_{4} \mathrm{AH}_{13}[10]$.

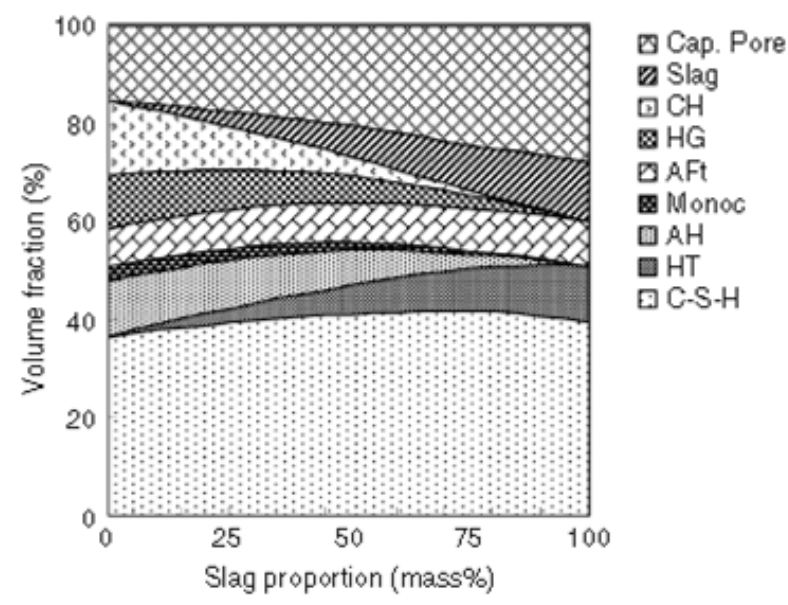

Figure 2. Volume fractions of hydration products and other phases in hydrating slag blended cement paste.

The study proposed and validated three reaction models for the slag-blended cement by quantifying the hydration products and determining the composition of C-S-H, whereby the hydration of calcium silicates in the clinker interacts with the slag hydration. $\mathrm{Al}_{2} \mathrm{O}_{3}$ compositional equilibrium of $\mathrm{C}-\mathrm{S}-\mathrm{H}$ is used in developing the models. Based on the investigations in their research W. Chen and H. J. H. Brouwers concluded that [10] Increasing the slag proportions in the cement increases the proportions of $\mathrm{C}$ $\mathrm{S}-\mathrm{H}$ in the hydration products. however Blending slag with Portland cement clearly lowers the $\mathrm{C} / \mathrm{S}$ ratio in $\mathrm{C}-\mathrm{S}$ $\mathrm{H}$ and increases the $\mathrm{A} / \mathrm{S}$ ratio.

\section{B. Glass content and hydraulic activity}

The glass content of slag is considered to be the most significant variable and certainly the most critical to hydraulicity. Several factors influence the degree of vitrification achieved during quenching, but the most important variable influencing the nature of slag is the temperature at which the furnace is tapped. The rate of quenching, which influences the glass content, is thus the predominant factor affecting the strengths of slag cements.

The chemical composition of the slag plays a key role upon which the HI has a bearing. From a chemical standpoint, slags can be classified into two types according to 
their basicity index. Several basicity indices have been defined by different authors, the simplest one being the $\mathrm{CaO} / \mathrm{SiO} 2$ ratio given S.C. Pal [22]. Metallurgists classify slag as either basic or acidic: the more basic the slag, the greater its hydraulic activity in the presence of alkaline activators. Variations in the $\mathrm{MgO}$ content up to about 8 $10 \%$ may have little effect on strength development, but high contents have an adverse effect[18]. Further, the presence of merwinite crystallites within the glass structure would improve the reactivity of slag. Moreover, it was observed that hydraulic activity increases with increasing $\mathrm{CaO}, \mathrm{Al} 2 \mathrm{O} 3$ and $\mathrm{MgO}$ and decreases with increasing $\mathrm{SiO} 2$ content[4,13].

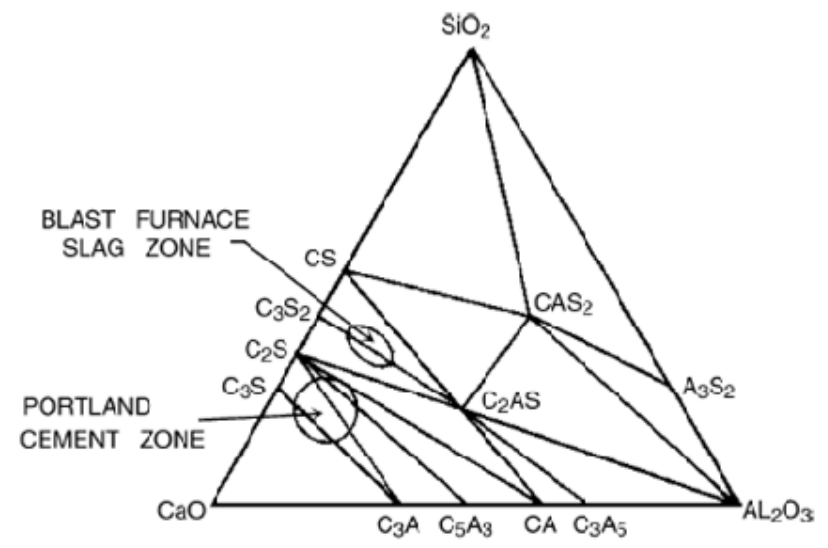

Figure 3. A ternary diagram indicating composition of $\mathrm{PC}$ and GGBFS in the $\mathrm{CaO}-\mathrm{SiO}_{2}-\mathrm{Al}_{2} \mathrm{O}_{3}$

Research carried out so far reveals that the hydration product that is formed when GGBFS is mixed with PC and water is essentially the same as the principal product formed when PC hydrates, i.e., calcium silicate hydrate (CSH). As seen in the ternary diagram in (fig 3), $\mathrm{PC}$ and GGBFS lie in the same general field, although PC is essentially in the C3S field, whereas GGBFS is found essentially in the C2S field of the diagram. This is why GGBFS hydrates are generally found to be more gel-like than the products of hydration of PC, and so add denseness to the cement paste. The hydration mechanism of GGBFS is different from that of cement $[22,20]$.

In general, hydration of GGBFS, in combination with $\mathrm{PC}$, at normal stage is a two-stage reaction. Initially and during the early hydration, the predominant reaction is with alkali hydroxide, but subsequent reaction is predominantly with calcium hydroxide. Hydraulic Index to assess more critically towards high svolume replacement of cement by slag and compare the same with other pozzolanic material, a new parameter, namely, Hydraulic Index (HI) could be introduced. Keil, whose work was covered by S.R. Pathak [20] has defined the HI of the slag based on $70 / 30$ as HI $70 / 30=((a-c) /(b-c)) \times 100$ where: $a=$ the strength of $70 \%$ slag $/ 30 \%$ PC at time $t ; b=$ the strength of $100 \%$ PC at time $\mathrm{t}$; $\mathrm{c}=$ the strength of $70 \%$ ground quartz $/ 30 \% \mathrm{PC}$ at time $\mathrm{t}$. This index gives a range of values from 0 to 100 or even greater, leading to a better range than that obtained in the ASTM SAI test, since the HI relates to the reactivity of the supplementary cementing material alone. The use of $70 \%$ slag content, higher than normally used, helps to distinguish the poor quality of slags from the good ones [22].

\section{Activation}

It has been unanimously agreed by different researchers that Slag cements take longer time to work and impart its properties to the cement it is blended with. The obvious reason for such property of slag could be its need for activation. Presence of activator can accelerate the break-up of structure and hydration of slags. The processes practically used for such processes are:

1. Alkali Activation
2. Thermal Activation

\section{1) Activation by alkalies}

Fathollah Sajedi [5] classified alkaline activators in six groups; where $\mathrm{M}$ is an alkaline:

1. Caustic alkalis, MOH.

2. Non-silicate weak acid salts: M2CO3, M2SO3, M3PO4, MF, etc.

3. Silicates, M2O_nSiO2.

4. Aluminates, $\mathrm{M} \overline{2} \mathrm{O} \_\mathrm{nA} 12 \mathrm{O} 3$.

5. Aluminosilicates, $\mathrm{M} 2 \mathrm{O} \_\mathrm{A} 12 \mathrm{O} 3 \_(2-6) \mathrm{SiO} 2$.

6. Non-silicate strong acid salts, M2SO4 .

Of all these activators, $\mathrm{NaOH}, \mathrm{Na} 2 \mathrm{CO} 3, \mathrm{Na} 2 \mathrm{O} \_\mathrm{nSiO} 2$ and $\mathrm{Na} 2 \mathrm{SO} 4$ are the most widely available and economical chemicals. Some potassium compounds have been used in laboratory studies. However, their potential applications will be very limited due to their availability and costs. Conversely, the properties of sodium and potassium compounds are very similar.

When the water/slag ratio is high, the initial porosity of the system is determined by the water/slag ratio. However, if the water/ slag ratio is low, compaction pressure will determine the initial porosity of the system [5]. GGBFS is a by-product of the iron making process and is produced by water quenching of molten blast furnace slag. The main constituents of GGBFS are $\mathrm{CaO}, \mathrm{SiO} 2, \mathrm{~A} 12 \mathrm{O} 3$ and $\mathrm{MgO}$. Slag shows primarily cementitious behavior but may also show some pozzolanic character (reaction with lime).Attempts have been made to overcome the problem of slow strength development in Portland slag cement [5]. Regarding replacement of clinker by slag, the problem of low early strength can be overcome by using an alkaliactivated slag (SSA) as the type of binder, which can potentially yield early high-strength concrete.

Several authors accepted that there exists two models of alkali-activation

1. The first one is the case of the activation of GGBFS $(\mathrm{Si}+\mathrm{Ca})$, with a mild alkaline solution having $\mathrm{CSH}$ as the main reaction products.

2 . In the second model of activation $(\mathrm{Si}+\mathrm{Al})$, the general example is the alkali-activation of metakaolin with medium to high alkaline solutions

$(\mathrm{Ca})^{2+}$ in the system is necessary to the formation of $\mathrm{C}-$ $\mathrm{S}-\mathrm{H}$ gel. In the presence of $(\mathrm{OH})^{-}$, provided by activator. There is an unanimous agreement that the reaction mechanism of alkali-activated binders, exist in a three step model of dissolution, orientation and hardening.

The reaction products depend also on the activator, the prime materials, and the systems $(\mathrm{Si}+\mathrm{Ca})$, which have a $\mathrm{C}-\mathrm{S}-\mathrm{H}$ gel as the main reaction product. As for the systems $(\mathrm{Al}+\mathrm{Si})$, the reaction products are Zeolite-like pol- 
ymers. The most commonly used alkaline activators are a mixture of sodium or potassium hydroxide $(\mathrm{NaOH}$ or $\mathrm{KOH})$, with sodium water glass $\left(\mathrm{nSiO}_{2} . \mathrm{Na}_{2} \mathrm{O}\right)$ or potassium water glass $\left(\mathrm{nSiO}_{2} \cdot \mathrm{K}_{2} \mathrm{O}\right)$. An increase was reported of about 40 to $90 \mathrm{MPa}$ after just one day of curing, when an alkaline activator with $\mathrm{NaOH}$ and water glass are used instead of just $\mathrm{NaOH}$. T. Barkharev [9] states that the nature of the activator influences the mechanical strength of alkali-activated slag mortars and that the optimum amount of $\mathrm{Na} 2 \mathrm{O}$ varies from $3 \%$ to $5.5 \%$ of the slag mass.

Fathollah Sejedi [5] distributed the alkalis into five groups (all percentages are by mass of slag)

1. The first group is sodium hydroxide.

2. The second activator is potassium hydroxide.

3. The third group is sodium silicate,

4. The fourth is a combined activator: ( $2 \%$ sodium silicate plus $0.6 \%$ sodium hydroxide) and the

5 . Last is $(0.5 \%$ sodium hydroxide plus $0.5 \%$ potassium hydroxide).

The results obtained in the experiments show that the mentioned activators do not have the same significance on the strengths. It seems the most relevant factor is the nature of the alkaline activator. For compressive strength, the relevance of factors may be attributed with age. This order seems be as: activator nature, activator concentration, and slag specific surface[3,5].

For years researchers have debated on whether to use $\mathrm{KOH}$ or Sodium Silicate for the alkali activation.

\section{a) Activation by sodium silicate}

Activation with sodium silicate (water glass) has been widely reported to give rise to rapid hardening and high compressive strengths. Problems, however, can be experienced with very short set times and subsequent shrinkage [2.3], and the activators used are often highly corrosive and would be difficult to handle safely outside of the laboratory. For the mix activated with $1.5 \mathrm{M}$ (modulus = 2) water glass and production slag. The strengths are high in comparison with equivalent OPC mixes.

\section{b) Activation with $\mathrm{KOH}$}

Activation with $\mathrm{KOH}$ gave a higher 1-day strength fig than activation with waterglass, but the subsequent strength development was much lower, and strengths at later ages were much lower for $\mathrm{KOH}$ activation relative to waterglass activation as shown in (fig4) $[3,11]$.

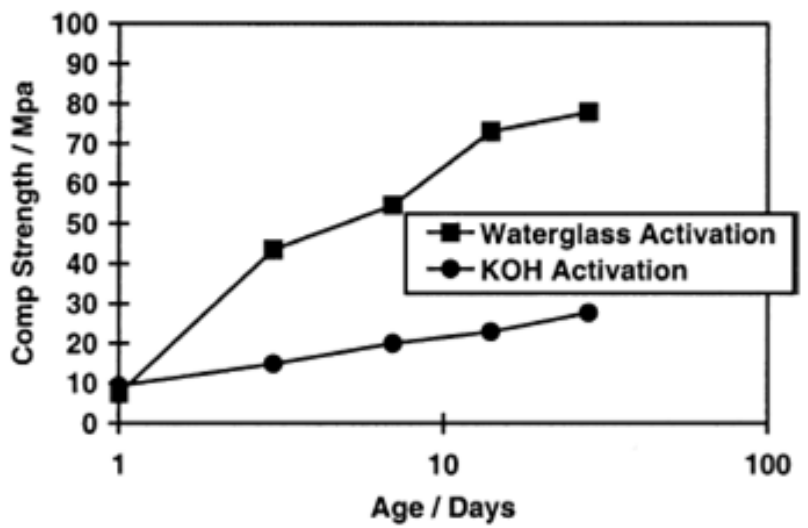

Figure 4. Strength development of slag activated with sodium silicate or with $5 \mathrm{M} \mathrm{KOH}$

\section{c) Effects of chemical activation}

Though the maximum obtained strength due to chemical activation is $85 \%$ of OM's strength at 56 days. Due to leaching in water cured regime, the strength of the specimens cured in the water were less than those cured in the air. In some mixes, strength loss has been observed. The results obtained show that strength loss in alkali-activated mortars depends on the level of slag used, the type and dosage of alkali activator, and the regime of curing[5].

\section{2) Thermal Activation}

Temperature variation caused by the heat of hydration, in mass concrete or the change of external environment, has a large influence on the mechanical properties of early-age concrete. Mechanical properties, such as compressive strength, are factors to be considered in the design and construction of concrete structures. In this investigation the effects of $50^{\circ} \mathrm{C}, 60^{\circ} \mathrm{C}$, and $70^{\circ} \mathrm{C}$ temperatures were studied on the early strengths at 3 and 7 days of $\mathrm{OSM} / 50$. It is clear that $60^{\circ} \mathrm{C}$ has the most enhancing effect on early-age strengths, so it is selected as the optimum temperature [8].

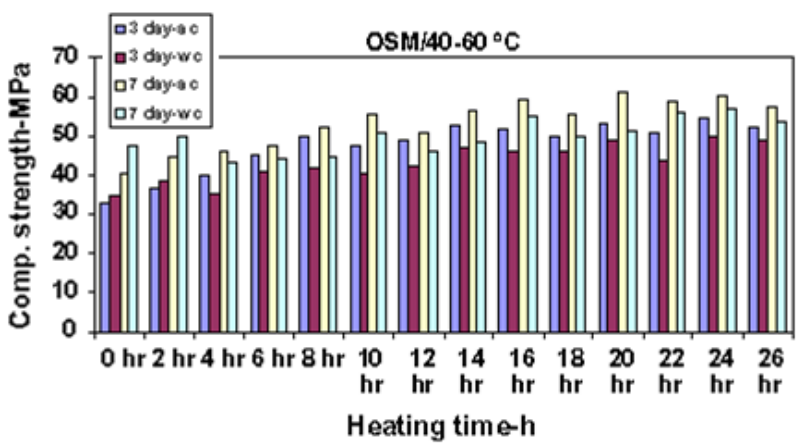

Figure 5. Comp. Strength vs. heating time for OSM/50 and OSM/40 cured in air and water

Hardened mortars and concretes can reach their maximum strength within several hours through elevated temperature curing. However, the ultimate strength of hardened mortars and concretes has been shown to decrease with curing temperature It is determined that $60^{\circ} \mathrm{C}$ is the optimum temperature. Duration of heating time is also very important for obtaining high early strength. For the slag used in this study, $20 \mathrm{~h}$ heating time is optimum. Usually, as heating time increases towards the optimum, the compressive strength will be increased [8].

It was seen that these strength levels are $21.78 \%$ and $20.00 \%$ more than that for OPC's specimens cured in the air, and $26.12 \%$ and $29.04 \%$ more than that for OPC's specimens cured in water, respectively. Also If the mortar is heated more than the optimum heating time, it is specified that this will not lead to an increase in the early strength of mortar.

\section{Durability Characteristics}

\section{1) Chloride ingress}

For finding the chloride ingress into concrete, G.J. Osborne [4] studied and experimented on meter blocks of concrete containing GGBS in the Tees Barrage, the cubes of concrete made with $70 \% \mathrm{GGBS} / 30 \%$ PC were placed upstream and downstream of the Tees Barrage.

It was reported that at low levels of slag replacement (about 35\%), the trend line remains nearly similar to that 
of the plain concrete [17]. Those with $60 \%$ slag tended to suffer some sea-water attack and had slightly higher chloride concentrations than those with $70 \%$ slag [4]. Concretes with $70 \%$ slag as replacement for Portland cement showed good strength development and suffered the least attack in the full-immersion zone, irrespective of the type of Portland cement or slag. Concretes with $80 \%$ slag had reduced strength development, but also had the lowest degree of chloride penetration, particularly when in combination with the medium $\mathrm{C}_{3} \mathrm{~A}$ PC.

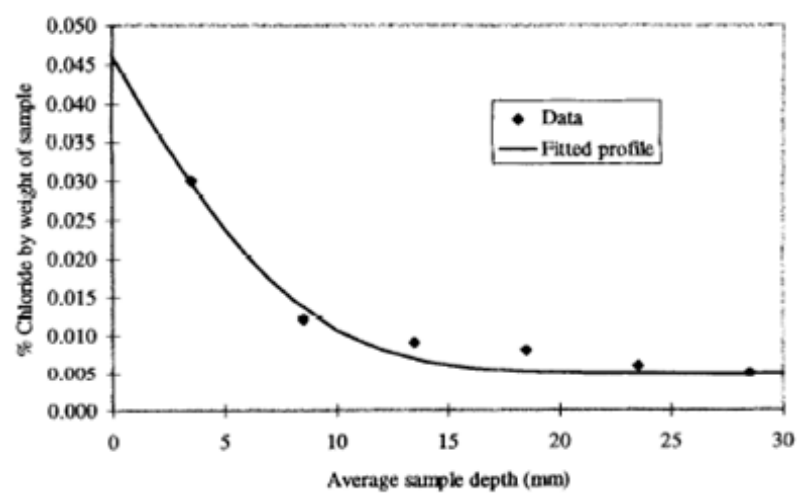

Figure 6. Chloride Ion penetration in meter blocks placed in river Tees Barrage.

Studies by S.Kumar [4] also depicted that adequate strength does not ensure low chloride permeability. There is a need to define and use an independent parameter to ensure low levels of chloride penetration [4]. Also increasing the $\mathrm{w} / \mathrm{c}$ ratio to 0.60 results in a substantial increase in chloride permeability of concrete without slag [16].

\section{2) Carbonation}

For finding the carbonation of concrete, G.J. Osborne [4] studied and experimented on meter blocks of concrete containing GGBS in the Tees Barrage England, the cubes of concrete made with $70 \%$ GGBS / $30 \%$ PC were placed upstream and downstream of the Tees Barrage. The depth of carbonation of these site-stored concretes, as measured by spraying the cores with phenolphthalein indicator, showed a wide range of values. the:

The two main factors influencing the carbonation were

1. Environmental conditions in which the concretes were situated

2. The level of slag as replacement for Portland cement.

Evidence showed that concretes with $50 \%$ slag as replacement achieved resistance to carbonation similar to that of normal Portland cement concretes of equivalent mixture proportions, in most indoor and outdoor environments [4]. However, carbonation was greater in the highslag-content $(70 \%)$ cements, especially if associated with a sheltered or drying microclimate These studies had shown that slag cement concretes, particularly at high levels of replacement, such as 70 and $80 \%$, carbonated significantly more than Portland cement concretes of similar mixture proportions when specimens were not moist cured and were subsequently stored in dry internal environments.

Carbonation was greater in the high slag- content concretes in these situations and they developed lower compressive strengths. For this series of concretes there was a good correlation between depth of carbonation and compressive strength at 28 days and later ages, with the carbonation depth varying proportionally to the square root of the age of the concrete [4].

\section{3) Sulphate Resistance}

Studies [4] have shown that the sulfate resistance of Portland and blast-furnace slag cement concretes is dependent upon the following criteria:

1. Curing regime

2. Cement type (C3A content of Portland cement and alumina content of slag)

3. The storage solution.

Even concretes demoulded after 1 day and placed in sulfate solution within the next few hours, showed better resistance to attack than specimens water-cured for up to 28 days to attain their design strength before immersion. This is at variance with the normal requirements and recommendations for the proper curing of concrete for most other applications, where there is a need to minimize the effects of carbonation and to attain optimum strength development [4].

The main chemical factors that influenced the sulfate resistance of Portland and blast-furnace slag cements were the $\mathrm{C} 3 \mathrm{~A}$ content of the Portland cement and the alumina level of the slag [13]. Low C3A, sulfate resisting Portland cement (SRPC) concretes were highly resistant to attack, as were combinations of the medium and high $\mathrm{C} 3 \mathrm{~A}$ normal Portland cements with low alumina slags. Sulfate attack was greatest when both the $\mathrm{C} 3 \mathrm{~A}$ content of the Portland cement and the alumina level of the slag were high. The level of replacement of normal Portland cement by slag was also important with 70 and $80 \%$ proving most beneficial, particularly for high $\mathrm{C} \&$ normal Portland cements, when substantial reductions in sulfate-ion ingress were realized [4].

\section{4) Freeze and thaw cycles}

All blast-furnace slag cement concretes in the tidal zone had suffered surface frost damage to some degree in the form of "pop-outs" and spalling that are characteristic of freezing and thawing attack. It was observed that this form of attack tended to occur during the first winter of exposure, when the concrete was relatively new and not fully cured. There were few, if any, signs of this progressing further at later ages [4]. The use of air entrainment should prevent this freezing and thawing attack [13]. There was no such damage with any of the fully immersed specimens or with the tidal portland cement concretes.

\section{5) Acid Attack}

The performance of slag cement concrete specimens stored in moorland water of $\% \mathrm{pH} 4.0$., but with little dissolved carbon dioxide, is being studied by Building Research Establishment at an exposure site in South Yorkshire in the UK. In general the quality of the concrete has been found to be of greater importance than the type of cement used in such aggressive solutions. However, the reduced calcium hydroxide content and lower porosity resulting from well-cured PC/slag concretes is generally regarded as being beneficial in reducing the rate of attack [4]. Marginal benefits have been achieved by using higher levels of slag as replacement for PC and this need to be substantiated at greater ages. 


\section{6) Surface scaling of concrete}

There have also been instances of scaling and surface softening of slag cement concretes in other climatic situations. Scaling or salt weathering is a phenomenon often observed at concrete structures along the Gulf coast, especially at the soil-air interface [13], The scaling was associated with early drying out of the surface layers and the resulting coarser pore structure. However, It was reported that the porous-permeable zone did not extend more than $15 \mathrm{~mm}$ into the concrete after 10 years of exposure, and is likely to be restricted to that. Generally the concrete was found to be sound, dense and with no sign of deterioration or cracks in the super or substructure. Highslag-cement concretes are more susceptible to drying out and reduced hydration during the early stages of curing, than normal Portland cement concretes. Though it was proved that after the concrete reaches a certain age, the negative durability characteristics start to decline and concrete becomes more and more stable in marine environments [19].

\section{CONCLUSIONS}

From the review, following conclusions were observed:

1. Slag is potentially an all purpose building material which can be used anywhere and in any type of construction.

2. An increase in fineness always encouraged to speed up hydration, increase setting time and improve most of the qualities of slag cement.

3. Though reactions of slag particles are slow, It can still be used with an activator, be it Thermal or Alkaline activator.

4. It has been unanimously agreed that water glass is a better activator than $\mathrm{KOH}$. But, owing to the negative effects of alkaline activator, Thermal activation is a better option. In Indian context, Thermal activation suits best owing to the temperature conditions in India.

5. The Durability criteria for slag cement offered several advantages, nemely low chloride ingress, high sulphate resistance and acid attack.

6. However slag cement still showed some disadvantages like high carbonation depth, low resistance to freeze and thaw cycles and surface scalling

\section{REFERENCES}

[1] Wang Qiang, Yan Peiyu. Hydration properties of basic oxygen furnace steel slag. Construction and Building Materials 24 (2010) 1134-1140. http://dx.doi.org/10.1016/j.conbuildmat.2009.12.028

[2] IS: 12089-1987. Indian Standards, Specification for Granulated Slag for the Manufacture of portland cement

[3] A.R. Brough, A. Atkinson. Sodium silicate-based, alkali-activated slag mortars. Part I. Strength, hydration and microstructure. Cement and Concrete Research 32 (2002) 865-879. http://dx.doi.org/10.1016/S0008-8846(02)00717-2
[4] G.J. Osborne. Durability of Portland blast-furnace slag cement concrete. Cement and Concrete Composites 21 (1999) 11-21. http://dx.doi.org/10.1016/S0958-9465(98)00032-8

[5] Fathollah Sajedi, Hashim Abdul Razak. The effect of chemical activators on early strength of ordinary Portland. Cement-slag mortars. Construction and Building Materials 24 (2010) 19441951. http://dx.doi.org/10.1016/j.conbuildmat.2010.04.006

[6] N.Y. Mostafa, S.A.S. El-Hemaly, E.L. Al-Wakeel, S.A. ElKorashy, P.W.Brown. Charaterization and evaluation of the hydraulic activity of water cooled slag and air cooled slag. Cement and concrete research $31 \quad$ (2001) 899-904. http://dx.doi.org/10.1016/S0008-8846(01)00497-5

[7] Folarin T. Olorunsogo and Peter J. Wainwrighe. Effect of GGBFS particle-size disttribution on mortar compressive strength.

[8] Fathollah Sajedi, Hashim Abdul Razak. Thermal activation of ordinary Portland cement-slag mortars. Construction and Building Materials 16 (2002) 489-494.

[9] Amit Raia, J. Prabakarb, C.B. Rajub, R.K. Morchalleb. Metallurgical slag as a component in blended cement. Construction and Building Materials 16 (2002) 489-494. http://dx.doi.org/10.1016/ S0950-0618(02)00046-6

[10] W. Chen and H. J. H. Brouwers. The hydration of slag, part 2: reaction models for blended cement. J Mater Sci (2007) 42:444464. http://dx.doi.org/10.1007/s10853-006-0874-1

[11] F. Bellmann, J. Stark. Activation of blast furnace slag by a new method. Cement and Concrete Research 39 (2009) 644-650. http://dx.doi.org/10.1016/j.cemconres.2009.05.012

[12] J.I. Escalante-Garcia a, L.J. Espinoza-Perez a, A. Gorokhovsky a, L.Y. Gomez-Zamorano. Coarse blast furnace slag as a cementitious material, comparative study as a partial replacement of Portland cement and as an alkali activated cement. Construction and $\begin{array}{llll}\text { Building } & \text { Materials } 23 & \text { (2009) } & 2511-2517 .\end{array}$ http://dx.doi.org/10.1016/j.conbuildmat.2009.02.002

[13] M.S. Shetty. Concrete Technology, Theory and Practice.

[14] P.E. Tsakiridis, G.D. Papadimitriou, S. Tsivilis, C. Koroneos. Utilization of steel slag for Portland cement clinker production. Journal of Hazardous Materials 152 (2008) 805-811. http://dx.doi.org/10.1016/j.jhazmat.2007.07.093

[15] Isa Yuksel, Omer Ozkan and Turhan Bilir. Use of Granulated Blast Furnace Slag in Concrete as fine as Fine aggregate. ACI Materials journal 103-M23.

[16] S. Kumar, B.K. Rao and S. Mishra. Chloride penetration resistance of concrete containing blast furnace slag. Indian concrete Journal, dec 2002, pp. 745-75.

[17] Michael D.A. Thomas, Allan Scott, Ted Bremner, Alain Bilodeau and Donna Day. Performance of slag Concrete in Marine Environment. ACI Materials journal 105-M71.

[18] S.C. Pal, A. Mukherjeeb, S.R. Pathak. Investigation of hydraulic activity of ground granulated blast furnace slag in concrete. Cement and Concrete Research 33 (2003) 1481-1486. http://dx.doi.org/10.1016/S0008-8846(03)00062-0

[19] Hua Xu, John L. Provis, Jannie S. J. van Deventer and Pavel V. Krivenko. Characterisation of Aged Slag Concrete. ACI Materials journal 105-M15.

[20] S. R. Pathak, S.C. Pal and A.Mukherjee. Evaluation of Hydraulic index for Indian GGBS. Indian concrete Journal, feb 2004, pp. 8791.

\section{AUTHOR}

Mohit Jain is with the Institute of Technology, Nirma University, Ahmedabad, India.

Submitted 16 September 2014. Published as resubmitted by the author 25 October 2014. 